\title{
Effects of fixed and removable space maintainers on halitosis
}

\author{
Elif Yıldızer Keriş ${ }^{1 *}$, Didem Atabek ${ }^{2}$ and Kahraman Güngör ${ }^{3}$
}

\begin{abstract}
Background: The current study evaluated the effects of fixed and removable space-maintainers on halitosis and oral health of children.

Methods: Forty-three patients randomly selected between the ages 4-10 whom fixed or removable space maintainers were indicated in Gazi University, Faculty of Dentistry, Department of Pedodontics. The inclusing criteria were: cariesfree (with/without restorations), with absence of periodontal diseases, without systematic disease, no mouth breathing and no use of antibiotics the 2-months period before the study. The patients were subdivided into two groups: the group treated with fixed space maintainers (group 1, $n=27$ ), the group treated with removable space maintainers (group $2, n=16)$. The the plaque index $(\mathrm{PI})$, gingival index $(\mathrm{Gl})$, periodontal screening index $(\mathrm{PSI})$, tongue coating index (TCI) records and the halitosis measurements were obtained at three time periods (T1: immediately after application, T2: 1 week after application, T3: 5 weeks after application). The measurement values of T1 served as control.
\end{abstract}

Results: No statistically significant difference was found in the PI, GI, PSI, TCl and halitosis measurements between T1-T2, T2-T3 and T1-T3 in both appliance groups and between the groups $(p>0.05)$.

Conclusions: The fixed and removable space maintainers did not affect oral health status and halitosis significantly.

Keywords: Space maintainers, Halitosis, Oral hygiene

\section{Background}

Halitosis or oral malodor is an unlikeable or bad odor arising from the oral cavity, which is a common problem that effects social relationships [1].

The etiological factors of halitosis include extrinsic and intrinsic causes $[2,3]$. The extrinsic causes are using tobacco, alcohol and some foods [4-6]. The intrinsic causes contain intra-oral and extra-oral causes [7]. Intraoral causes are related with oral hygiene problems and oral diseases such as tongue coating, periodontal disease, extensive dental caries, pericoronitis, impacted food, unclean denture, stomatitis, xerostomia and habitual mouth breathing [1, 8-10]. Extra-oral causes are systemic diseases and some medications that effects the oral odor $[1,8,11]$. Oral conditions are responsible for halitosis in nearly $90 \%$ of all cases $[2,12]$.

The three main methods for measuring and assessing the halitosis are organoleptic measurement, gas chromatography,

\footnotetext{
*Correspondence: dtelifkaya@gmail.com

'Department of Radiology, Çanakkale Dentistry Hospital, 1700, Kepez,

Çanakkale, Turkey

Full list of author information is available at the end of the article
}

and sulfide monitoring. In organoleptic method, the physician is smelling the exhaled air of mouth and nose while the patient is breathing and speaking and halitosis is assessed using a score of $0-5$. Organoleptic assessment is considered as a suitable method for detecting halitosis but has some disadvantages such as being subjective [13]. Gas chromatography and portable sulfide monitor have been developed to evaluate halitosis objectively. Methyl mercaptan, hydrogen sulfide, butyric acid, proprionic acid and valeric acid are called as volatile sulphur components (VSCs) and these components are major cause of halitosis [14]. These components are occured as a result of the anaerobic bacteria by metabolizing different cells/tissues located in the mouth $[14,15]$. Portable sulphur monitors (Halimeters) and gas chromatography measure the total concentration of sulphur compounds.

Space main-tainers are found to be associated with increased plaque accumulation [16]. Furthermore, the correlation between plaque accumulation and halitosis is clearly demonstrated in the literature [17]. Numerous 
studies have reported on the increased halitosis in patients using orthodontic appliances [18, 19]; however, there are no published studies relating to halitosis in conjunction with the use of fixed and removable space maintainers. Thus, the present study was aimed at investigating the effects of fixed and removable space maintainers on periodontal health and on halitosis.

\section{Methods}

Ethical approval for this study was obtained from the Ethical Committee of the Faculty of Dentistry, University of Ankara. The study population was composed of 43 patients randomly selected between the ages 4-10 whom fixed or removable space maintainers were indicated in Gazi University, Faculty of Dentistry, Department of Pedodontics. All patients/parents were informed and their consent was given prior to entering the study. The inclusing criteria for this study were: caries-free (with/without restorations), with absence of periodontal diseases, without systematic disease, no mouth breathing and no use of antibiotics the 2-months period before the study.

The patients were subdivided into two groups randomly: the group treated with fixed space maintainers (group 1, $n=27,14$ girls, 13 boys), the group treated with removable space maintainers (group 2, $n=16$, nine girls, seven boys). Oral hygiene instructions were given to all patients and their parents 1 week before the beginning of the study by a pediatric dentist (D.A.) and patients were asked to brush their teeth and tongue supervised by their parents. To standardize the patient population, only bandand-loop type space maintainers were included in the fixed space maintainer group. All removable space maintainers were made of an acrylic base and retention elements (vestibul arch, Adam's and C clasps).

At three time periods (T1: immediately after application, T2: 1 week after application, T3: 5 weeks after application), patients were clinically examined by the same pediatric dentist (D.A.) trained in the use of the assessment clinical parameters used in the study and the halitosis measurements were obtained. The measurement values of T1 served as control.

\section{Clinical evaluation}

Immediately prior to placement of the space maintainers, the plaque index (PI), gingival index (GI) [20], periodontal screening index (PSI) [21] (using a manual North Carolina 15 periodontal probe) were measured at the mid facial, mid lingual, and buccal line angles of the teeth which are one each of the maxillary right or left molars and and the antagonist teeth, mandibular right or left molars and the antagonist teeth, maxillary or mandibular incisors and the antagonist teeth.

Tongue coating was recorded according to the Miyazaki tongue coating index (TCI) [14].

\section{Halitosis measurements}

For determininig halitosis and the level of detection, measurements were done according to organoleptic assessment and using portable sulphur monitor (Halimeters, Interscan corporation, Chatsworth, CA, USA).

The subjects were instructed to refrain from eating (especially garlic and onion), drinking coffee, eating mints, using minted chewing gum or scented oral hygiene products, and rinsing their mouths for $2 \mathrm{~h}$ before the examination. All measurements were recorded between 8:30 and 11:30 $\mathrm{h}$ (before lunch).

VSC concentrations were measured using a Halimeter (Model No. RH17R; Chatsworth, CA). The subject was asked to close his or her mouth and to breathe through the nose for $3 \mathrm{~min}$ before the Halimeter reading was taken. It was used according to the manufacturer's instructions with a newly calibrated detector. The subject was asked not to exhale or inhale while the Halimeter reading was collected. The highest score was recorded, and the procedure was repeated twice at 3-min intervals, resulting in three Halimeter readings, from which a mean odor score was calculated. The mean value was calculated in parts per billion (ppb) for each patient. According to the manufacturer, halitosis is present at a VSC value $>110 \mathrm{ppb}$.

\section{Statistical analysis}

Power analysis showed that for a power of 0.80 with an $\alpha$ error of $0.05,16$ patients would be required for each group.

The records were statistically analyzed by using SPSS (version 17.0; SPSS Inc, Chicago, Ill). The KolmogorovSmirnov test was applied to test for normal distribution. Comparisons of parameters in the groups and times were evaluated according to two-way variance analysis (ANOVA), Chi-Square test and Fisher's Exact test and and $p<0.05$ set for level of significance.

\section{Results}

\section{Clinical measurements}

Values for clinical parameters at T1,T2 and T3 of the groups are provided in Table 1 and Figs. 1 and 2.

No statistically significant difference was found in the PI, GI, PSI and TCI variable between T1-T2, T2-T3 and $\mathrm{T} 1-\mathrm{T} 3$ in both appliance groups and between the groups (Chi-Square, $p=1.00>0.05$ ). Grade 1 of the plaque index was found with 26 of 27 patients and one of the patients recorded as grade 2 in fixed space maintainer group, and all af the patients with removable space maintainer recorded as grade 1 at T1. However the plaque scores decreased over time.

PSI, GI scores were found mostly grade 0 and were found under grade 2 with almost all of the patients of both appliance groups over all time. 
Table 1 Values for clinical parameters at T1, T2 and T3 of the groups

\begin{tabular}{|c|c|c|c|}
\hline & T1 & $\mathrm{T} 2$ & $\overline{\mathrm{T} 3}$ \\
\hline \multicolumn{4}{|l|}{ Fixed applience group } \\
\hline \multicolumn{4}{|l|}{ PI (Plaque Index) } \\
\hline Grade 0: No plaque & 0 & 0 & 0 \\
\hline Grade 1: Not visible thin coating of plaque which is only visible after using the probe & 26 & 27 & 27 \\
\hline Grade 2: Moderate accumulation of plaque, visible with the naked eye, but not filling interdental space & 1 & 0 & 0 \\
\hline Grade 3: Abundance of plaque, filling interdental space & 0 & 0 & 0 \\
\hline \multicolumn{4}{|l|}{ Gl (Gingival Index) } \\
\hline Grade 0: No inflammation. & 26 & 25 & 26 \\
\hline Grade 1: Mild inflammation, slight change in color, slight edema, no bleeding on probing. & 1 & 2 & 1 \\
\hline Grade 2: Moderate inflammation, moderate glazing, redness, bleeding on probing. & 0 & 0 & 0 \\
\hline Grade 3: Marked redness and edema, ulceration with tendency to spontaneous bleeding. & 0 & 0 & 0 \\
\hline \multicolumn{4}{|l|}{ PSI (Periodontal Screening Index) } \\
\hline Grade 0: No bleeding on probing, no pathologic pocket, no calculus & 26 & 26 & 26 \\
\hline Grade 1: Bleeding on probing up to $1 \mathrm{~mm}$ & 1 & 1 & 1 \\
\hline Grade 2: Calculus and no pathologic pocket & 0 & 0 & 0 \\
\hline Grade 3: Probing depth $3.5-5.5 \mathrm{~mm}$ & 0 & 0 & 0 \\
\hline Grade 4: Probing depth $>5.5 \mathrm{~mm}$ & 0 & 0 & 0 \\
\hline \multicolumn{4}{|l|}{ TCI (Tongue Coating Index) } \\
\hline Grade 0: No visible coating & 18 & 22 & 17 \\
\hline Grade 1: Less than a third of tongue dorsum is covered & 8 & 4 & 9 \\
\hline Grade 2: Less than two thirds of tongue dorsum is covered & 1 & 1 & 1 \\
\hline Grade 3: More than two thirds of tongue dorsum is covered & 0 & 0 & 0 \\
\hline \multicolumn{4}{|l|}{ Removable applience group } \\
\hline \multicolumn{4}{|l|}{ PI (Plaque Index) } \\
\hline Grade 0: No plaque & 0 & 0 & 2 \\
\hline Grade 1: Not visible thin coating of plaque which is only visible after using the probe & 16 & 16 & 14 \\
\hline Grade 2: Moderate accumulation of plaque, visible with the naked eye, but not filling interdental space & 0 & 0 & 0 \\
\hline Grade 3: Abundance of plaque, filling interdental space & 0 & 0 & 0 \\
\hline \multicolumn{4}{|l|}{ Gl (Gingival Index) } \\
\hline Grade 0: No inflammation. & 14 & 14 & 14 \\
\hline Grade 1: Mild inflammation, slight change in color, slight edema, no bleeding on probing. & 2 & 2 & 2 \\
\hline Grade 2: Moderate inflammation, moderate glazing, redness, bleeding on probing. & 0 & 0 & 0 \\
\hline Grade 3: Marked redness and edema, ulceration with tendency to spontaneous bleeding. & 0 & 0 & 0 \\
\hline \multicolumn{4}{|l|}{ PSI (Periodontal Screening Index) } \\
\hline Grade 0: No bleeding on probing, no pathologic pocket, no calculus & 15 & 15 & 15 \\
\hline Grade 1: Bleeding on probing up to $1 \mathrm{~mm}$ & 1 & 1 & 1 \\
\hline Grade 2: Calculus and no pathologic pocket & 0 & 0 & 0 \\
\hline Grade 3: Probing depth $3.5-5.5$ mm & 0 & 0 & 0 \\
\hline Grade 4: Probing depth $>5.5 \mathrm{~mm}$ & 0 & 0 & 0 \\
\hline \multicolumn{4}{|l|}{ TCI (Tongue Coating Index) } \\
\hline Grade 0: No visible coating & 9 & 11 & 13 \\
\hline Grade 1: Less than a third of tongue dorsum is covered & 6 & 5 & 3 \\
\hline Grade 2: Less than two thirds of tongue dorsum is covered & 1 & 0 & 0 \\
\hline Grade 3: More than two thirds of tongue dorsum is covered & 0 & 0 & 0 \\
\hline
\end{tabular}




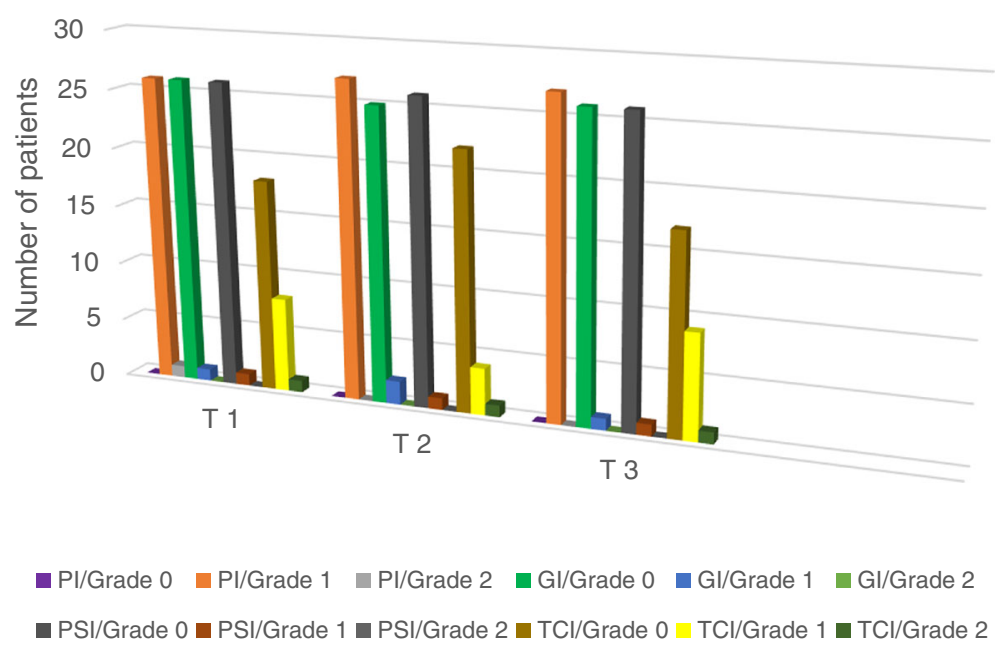

Fig. 1 Values for clinical parameters at T1, T2 and T3 of the fixed applience group

TCI was decreased by time in removable space maintainer group. Only one patient's TCI scores with fixed sapace maintainer increased at T3.

\section{Halitosis measurements}

No statistically significant difference was found in halitosis values between $\mathrm{T} 1-\mathrm{T} 2, \mathrm{~T} 2-\mathrm{T} 3$ and $\mathrm{T} 1-\mathrm{T} 3$ in both appliance groups (Two-Way ANOVA, $p=0.917>0.05$ ) and between groups (Two-Way ANOVA, $p=0.709>$ 0.05). In both groups, halitosis values decreased at T3 but statistically non significant (Table 2 and Fig. 3).

\section{Discussion}

The use of space maintainers has been stated to result in an increased plaque accumulation, which can lead to periodontal disease $[16,22]$. Previous studies have revealed that the presence of gingivitis or periodontitis increases the risk of developing halitosis [23-25]. There are limited numbers of studies evaluating the effects of space maintainers on periodontal status $[16,26]$ however, of these, none of them investigated the effects of space maintainers on halitosis.

In this study patients were instructed to brush both teeth and tongue because previous studies indicated that increase in tongue coating and periodontal diseases were two major causes for halitosis $[27,28]$.

In previous studies, the effects of space maintainers and orthodontic appliances on periodontal indices were evaluated with longer periods of follow-up [16, 26, 29]. Altough, following-up with longer periods is required to evaluate more accurately, patient cooperation, motivation for oral hygiene procedures, and eating habits can change with time [30]. Therefore, based on previous studies, this study was terminated in the 5th week [30-33].

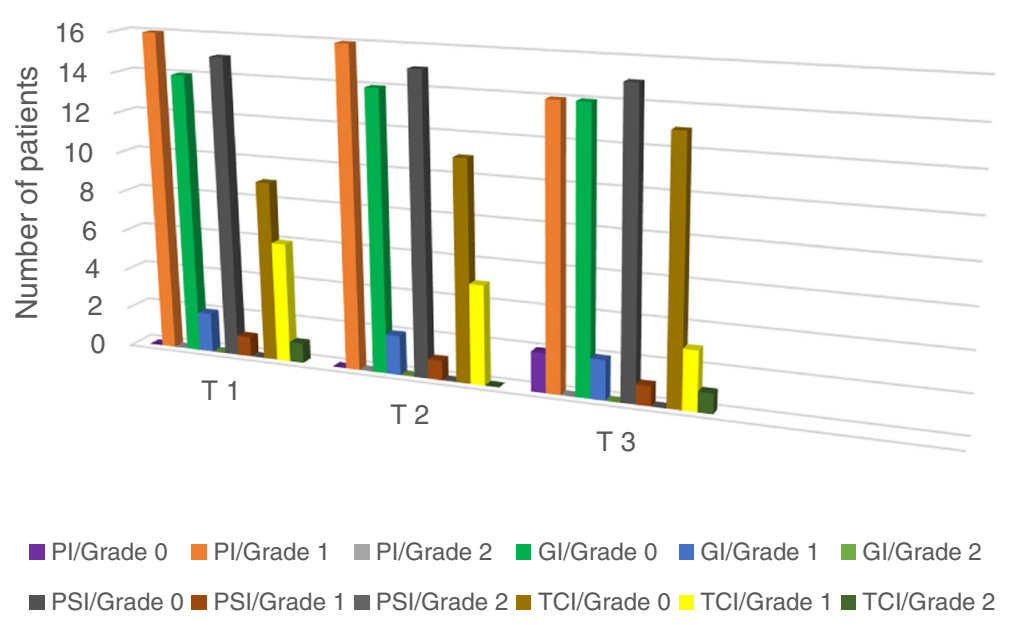

Fig. 2 Values for clinical parameters at T1, T2 and T3 of the removable applience group 


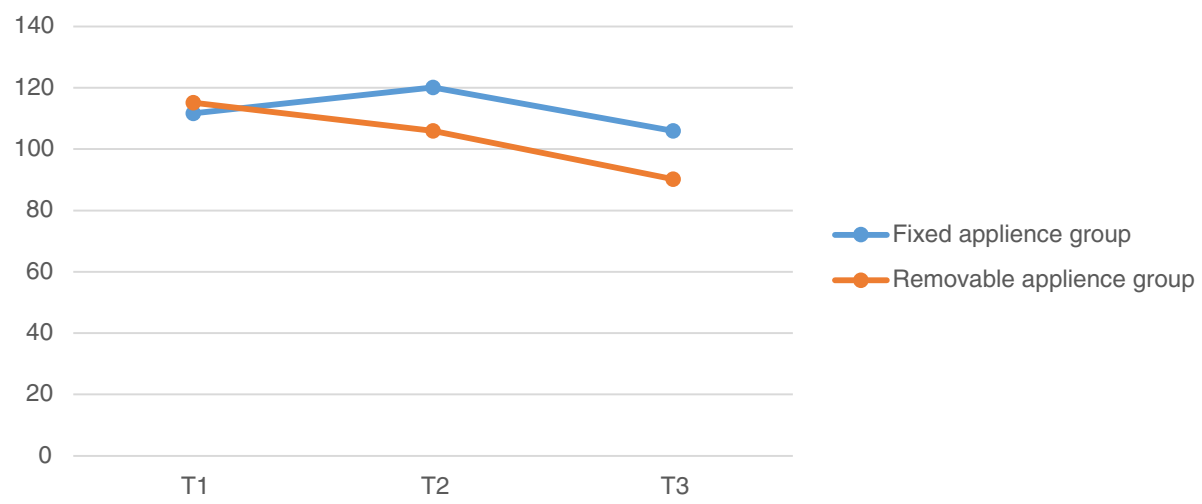

Fig. 3 Mean halitosis scores of groups at three evaluation times

According to our results for plaque index, grade 1 of the plaque index was found with 26 of 27 patients and one of the patients recorded as grade 2 in fixed space maintainer group, and all af the patients with removable space maintainer recorded as grade 1 at $\mathrm{T} 1$. It seems it was difficult to perform adequate oral hygiene despite careful instruction because younger patients can remove plaque over the surface much worse. However the plaque scores decreased over time. It could be due to the Hawthorne effect, a phenomenon where subjects improve or modify their behavior when they know they are being observed [34] .

Compatible with decreasing in plaque scores, the results of this study showed no significant differences in PSI, GI values during the treatment/observation time in all the groups. Anyway, our patients' PSI, GI scores were under grade 1 mostly over all time.

Studies which are evaluating the effects of space maintainers on periodontal conditions are very rare $[16,26]$. Methodologies of these previous studies are different from our study because these studies compared the plaque, gingival and bleeding on probing index scores in regions where space maintainers were present (test teeth) with in regions where space maintainers were not present (opposing teeth). We did not diveded the teeth as test and opposing during statistical analysis because halitosis measurements would be affected by periodontal status both of the teeth which were related and unrelated to space maintainers. One of these previous studies by Arikan V et al. [26] revealed that the removable space maintainers did not affect plaque accumulation in test teeth. In addition, they found that the plaque scores of fixed space maintainers in test teeth were lower at time of 6th month than baseline. At the same time, the authors reported that the gingival indices and bleeding on probing scores did not significantly differ between the regions with and without removable space maintainers, and there was not any negative effect of fixed space maintainers on periodontal status in test teeth at 6th month. Although the statistical analysis vary from those in our study, their results are in accordence with our results. In contrast to our study, the other previous study by Arikan F et al. [16], observed that both fixed and removable space maintainers cause an increase in plaque accumulation in all teeth, and an increase in bleeding index and pocket depth in test teeth, nevertheless removable appliance group showed less increase. Overall decreases in the index scores in our study may result from good oral hygiene unrelated to space maintainer use.

The effects of removable and fixed orthodontic appliances on periodontal health have been studied previously. The results of this present study are incompatible with the previous studies that suggest a strong relationship between orthodontic appliance treatment and plaque accumulation and increasing periodontal indices [18, 30, 33]. Similiarly with our findings, other studies reported decreasing in plaque indices and improvement of periodontal health $[29,35]$. These different results may be related to the study design such as the different age groups, appliances used, observation time, the level of oral hygiene of the subjects and statistical analyses.

Tongue cleaning was in accordance with decreased halitosis scores in this study. Recent studies showed

Table 2 Mean halitosis scores of groups at three evaluation times

\begin{tabular}{llll}
\hline & T1 & T2 & T3 \\
& Mean \pm SD & Mean \pm SD & Mean \pm SD \\
\hline Fixed applience group & $111,7037 \pm 63,6884$ & $120,1852 \pm 73,9491$ & $105 \pm 46,7596$ \\
Removable applience group & $115,125 \pm 89,0654$ & $105,9375 \pm 53,7407$ & $90,25 \pm 50,0473$ \\
\hline
\end{tabular}


that tongue cleaning may positively affect the halitosis scores [29].

The organoleptic assessment is preferable for the daily practice for diagnosis of bad breath because it is simple to perform and does not require a device. But organoleptic method has some advantages such as not being reproducible, having crossinfection risks and can be affected by the examiner [36-38]. It has been reported that gas chromatography is reliable, objective and reproducible method for detecting halitosis [39]. However, these devices are complex, not portable and expensive, requires the user's experience [40]. In order to overcome these practical drawbacks, portable sulphur monitors (Halimeters) is preferred for routine use in the dental clinic. The Halimeter does not need experienced personnel and easy to perform [39]. But Halimeter can only measure the VSCs, the organoleptic method is superior for assessing halitosis caused by non-sulphide components [13]. However, recent studies have concluded that the recorded data of Halimeter is correlated with the data of organoleptic method for diagnosing halitosis [41].

In both groups, halitosis values decreased at T3 but statistically non significant. Decreased halitosis scores were in accordance with improved oral healh status. It was not possible to compare the results of our study with other experiments, since the documents about the effect of space maintainers on the halitosis of children is lacking and studies are mostly performed on children receiving orthodontic treatment. It is demonstrated that orthodontic treatment effects halitosis. Kaygisiz et al. [29] evaluated the effect of fixed orthodontic treatment on oral malodor. They evaluated halitosis values of patients treated with fixed orthodontic appliances. The authors found nonsignificant decreases 4 and 8 weeks after bonding in the fixed orthodontic appliance group, which is similar with our study.

A limitation of this study could be the lack of data on the organoleptic scores of the patients. Assessing halitosis by organoleptic method appears sensible, it has been suggested that halitosis should be diagnosed with two different methods, organoleptic and instrumental measurements [41]. Because of the cross-infection risks of organoleptic measurement, only Halimeter used in this research.

\section{Conclusions}

The fixed and removable space maintainers did not affect oral health status and halitosis significantly.

\section{Abbreviatıons}

ANOVA: Two-way variance analysis; Gl: Gingival index; PI: Plaque index; ppb: parts per billion; PSI: Periodontal screening index; T1: Immediately after application; T2: 1 week after application; T3: 5 weeks after application; TCl: Tongue coating index; VSCs: Volatile sulphur components
Acknowledgements

Not applicable.

Funding

Not applicable.

\section{Avallability of data and materials}

We state that the clinical data and personal details will not be made available in order to protect the participants identity.

\section{Authors' contributions}

EYK carried out the halitosis measurements, trained DA for the use of the assessment clinical parameters used in the study, participated in the design of the study and drafted the manuscript. DA clinically examined the patients participated in the study. KG participated in the design of the study and performed the statistical analysis. All authors read and approved the final manuscript.

\section{Authors' information}

EYK: DDS PHD, Dentomaxillofacial radiologist, Çanakkale Dentistry Hospital, Department of Radiology, 1700, Kepez, Çanakkale, Turkey, DA: Associate Professor, Gazi University, Faculty of Dentistry, Department of Pediatric Dentistry, 06510, Emek, Ankara, Turkey, KG: Associate Professor, Gazi University, Faculty of Dentistry, Department of Oral Diagnosis and Radiology, 06510, Emek, Ankara, Turkey.

Competing interests

The authors declare that they have no competing interests.

\section{Consent for publication}

Not applicable.

\section{Ethics approval and consent to participate}

Ethical approval for this study was obtained from the Ethical Committee of the Faculty of Dentistry, University of Ankara. All patients/parents were informed and their consent was given prior to entering the study.

\section{Author details}

'Department of Radiology, Çanakkale Dentistry Hospital, 1700, Kepez, Çanakkale, Turkey. ${ }^{2}$ Department of Pediatric Dentistry, Gazi University, Emek, Ankara 06510, Turkey. ${ }^{3}$ Department of Oral Diagnosis and Radiology, Gazi University, Emek, Ankara 06510, Turkey.

Received: 12 June 2016 Accepted: 15 September 2016 Published online: 22 September 2016

\section{References}

1. Hughes FJ, McNab R. Oral malodour a review. Arch Oral Biol. 2008:53:1-7.

2. ADA Council on Scientific Affairs. Oral malodor. J Am Dent Assoc. 2003;134: 209-14.

3. Yaegaki K, Coil JM. Examination, classification, and treatment of halitosis; clinical perspectives. J Can Dent Assoc. 2000;66:257-61.

4. Al-Ansari JM, Boodai H, Al-Sumait N, Al-Khabbaz AK, Al-Shammari KF, Salako N. Factors associated with self-reported halitosis in Kuwaiti patients. J Dent. 2006:34:444-9.

5. Nalcaci R, Baran I. Factors associated with selfreported halitosis $(\mathrm{SRH})$ and perceived taste disturbance (PTD) in elderly. Arch Gerontol Geriatr. 2008;46: 307-16

6. Porter SR, Scully C. Oral malodour (halitosis). BMJ. 2006:333:632-5.

7. Sanz M, Roldan S, Herrera D. Fundamentals of breath malodour. J Contemp Dent Pract. 2001;2:1-17.

8. van den Broek AM, Feenstra L, de Baat C. A review of the current literature on aetiology and measurement methods of halitosis. J Dent. 2007;35:627-35

9. Nalcaci R, Baran I. Oral malodor and removable complete dentures in the elderly. Oral Surg Oral Med Oral Pathol Oral Radiol Endod. 2008;105:5-9.

10. Kanehira T, Takehara J, Takahashi D, Honda O, Morita M. Prevalence of oral malodor and the relationship with habitual mouth breathing in children. Clin Pediatr Dent. 2004;28:285-8.

11. Dal Rio AC, Nicola EM, Teixeira AR. Halitosis an assessment protocol proposal. Braz J Otorhinolaryngol. 2007;73:835-42. 
12. Delanghe G, Ghyselen J, van Steenberghe D, Feenstra L. Multidisciplinary breath-odour clinic. Lancet. 1997;350(9072):187.

13. Tonzetich J. Oral malodor: an indicator of health status and oral cleanliness. Int Dent J. 1978:28:309-19.

14. Miyazaki H, Sakao S, Katoh Y, Takehara T. Correlation between volatile sulphur compounds and certain oral health measurements in the general population. J Periodontol. 1995;66:679-84.

15. Moriyama T. Clinical study of the correlation between bad breath and subgingival microflora. Shikwa Gakuho. 1989;89:1425-39.

16. Arikan F, Eronat N, Candan U, Boyacıoğlu H. Periodontal conditions associated with space maintainers following two different dental health education techniques. J Clin Pediatr Dent. 2007;31:229-34.

17. Tonzetich J. Production and origin of oral malodor: a review of mechanisms and methods of analysis. J Periodontol. 1977:48:13-20.

18. Zurfluh MA, van Waes HJ, Filippi A. The influence of fixed orthodontic appliances on halitosis. Schweiz Monatsschr Zahnmed. 2013;123:1064-75.

19. Nalçacı R, Ozat Y, Cokakoğlu S, Türkkahraman H, Onal S, Kaya S. Effect of bracket type on halitosis, periodontal status, and microbial colonization. Angle Orthod. 2014;84:479-85.

20. Silness P, Löe H. Periodontal disease in pregnancy II. Correlation between oral hygiene and periodontal condition. Acta Odontol Scand. 1964;22:121-35.

21. Willershausen B, Kasaj A, Willershausen I, Zahorka D, Briseño B, Blettner M, Genth-Zotz S, Münzel T. Association between chronic dental infection and acute myocardial infarction. J Endod. 2009;35:626-30.

22. Arendorf T, Addy M. Candidal carriage and plaque distribution before, during and after removable orthodontic appliance therapy. J Clin Periodontol. 1985;12:360-8.

23. Morita M, Wang HL. Association between oral malodor and adult periodontitis: a review. J Clin Periodontol. 2001;28:813-9.

24. Lu DP. Halitosis: An etiologic classification, a treatment approach and prevention. Oral Surg Oral Med Oral Pathol. 1982;54:521-6.

25. Ratcliff PA, Johnson PW. The relationship between oral malodor, gingivitis and periodontitis. A review. J Periodontol. 1999;70:485-9.

26. Arikan V, Kizilci E, Ozalp N, Ozcelik B. Effects of Fixed and Removable Space Maintainers on Plaque Accumulation, Periodontal Health, Candidal and Enterococcus Faecalis Carriage. Med Princ Pract. 2015;24:311-7.

27. Miyazaki H, Sakao S, Katoh Y, Takehara T. Correlation between volatile sulphur compounds and certain oral health measurements in the general population. J Peridontol. 1995;66:679-84.

28. Takeshita T, Suzuki N, Nakano Y, et al. Relationship between oral malodor and the global composition of indigenous bacterial populations in saliva. Appl Environ Microbiol. 2010;76:2806-14.

29. Kaygisiz E, Uzuner FD, Yuksel $S$, Taner $L$, Çulhaoğlu R, Sezgin Y, Ateş C. Effects of self-ligating and conventional brackets on halitosis and periodontal conditions. Angle Orthod. 2015;85:468-73.

30. Nalçacı R, Özat Y, Çokakoğlu S, Türkkahraman H, Önal S, Kaya S. Effect of bracket type on halitosis, periodontal status, and microbial colonization. Angle Orthod. 2014;84(3):479-85.

31. Babacan H, Sokucu O, Marakoglu I, Ozdemir H, Nalcacı R. Effects Of fixed appliances on oral malodor. Am J Orthod Dentofac Orthop. 2011;139: 351-5.

32. Pellegrini $P$, Sauerwein $R$, Finlayson $T$, et al. Plaque retention by self-ligating vs. elastomeric orthodontic brackets: quantitative comparison of oral bacteria and detection with adenosine triphosphate-driven bioluminescence. Am J Orthod Dentofac Orthop. 2009:135:426.

33. Turkkahraman H, Sayin MO, Bozkurt FY, Yetkin Z, Kaya S, Onal S. Archwire ligation techniques, microbial colonization, and periodontal status in orthodontically treated patients. Angle Orthod. 2005;75:231-6.

34. Feil PH, Grauer JS, Gadbury-Amyot CC, Kula K, McCunniff MD. Intentional use of the Hawthorne effect to improve oral hygiene compliance in orthodontic patients. J Dent Educ. 2002:66:1129-35.

35. Karkhanechi M, Chow D, Sipkin J, Sherman D, Boylan RJ, Norman RG, Craig RG, Cisneros GJ. Periodontal status of adult patients treated with fixed buccal appliances and removable aligners over one year of active orthodontic therapy. Angle Orthod. 2013;83:146-51.

36. Rosenberg M, McCulloch CA. Measurement of oral malodor: current methods and future prospects. J Periodontol. 1992;63:776-82.

37. Seemann R, Passek G, Zimmer S, Roulet JF. The effect of an oral hygiene program on oral levels of volatile sulfur compounds (VSC). J Clin Dent. 2001;12:104-7.
38. Vandekerckhove B, Van den Velde S, De Smit M, Dadamio J, Teughels W, Van Tornout M, Quirynen M. Clinical reliability of non-organoleptic oral malodour measurements. J Clin Periodontol. 2009;36:964-9.

39. Murata T, Yamaga T, lida T, Miyazaki H, Yaegaki K. Classification and examination of halitosis. Int Dent J. 2002;52:181-6.

40. Furne J, Majerus G, Lenton P, Springfield J, Levitt DG, Levitt MD. Comparison of volatile sulfur compound concentrations measured with a sulfide detector vs. gas chromatography. J Dent Res. 2002;81:140-3.

41. Brunner F, Kurmann M, Filippi A. The Correlation of Organoleptic and Instrumental Halitosis Measurement. Schweiz Monatsschr Zahnmed. 2010; 120:402-5.

\section{Submit your next manuscript to BioMed Central and we will help you at every step:}

- We accept pre-submission inquiries

- Our selector tool helps you to find the most relevant journal

- We provide round the clock customer support

- Convenient online submission

- Thorough peer review

- Inclusion in PubMed and all major indexing services

- Maximum visibility for your research

Submit your manuscript at www.biomedcentral.com/submit
Biomed Central 